\title{
Cerebrospinal fluid penetration of very high-dose meropenem: a case report
}

CrossMark

\author{
Thomas Kerz $^{1 *} \mathbb{D}$, Friederike D. von Loewenich², Jason Roberts ${ }^{3,4,5,6}$, Axel Neulen ${ }^{1}$ and Florian Ringel ${ }^{1}$
}

\begin{abstract}
Background: Standard dosing of meropenem ( $2 \mathrm{~g}$ t.i.d.) produces CSF concentrations of only $1-2 \mathrm{mg} / \mathrm{L}$ which is inferior to the clinical breakpoint for most Gram-negative bacteria. There is therefore concern that dosing must be increased in order to achieve therapeutic CSF concentrations for bacteria with susceptibility close to clinical breakpoints. Yet, the effects of high-dose meropenem on CSF concentrations are not well described in literature. We therefore determined meropenem CSF-levels in a patient who was treated with $15 \mathrm{~g} /$ day of meropenem.

Case presentation: Our patient suffered from a brain trauma and an external ventricular drainage was implanted. Later, a carbapenemase-producing Acinetobacter baumannii (OXA-23, NDM-1) was isolated from blood cultures and CSF. The MIC for meropenem was $>32 \mathrm{mg} / \mathrm{L}(\mathrm{R})$, and we opted for a combination therapy of meropenem, colistin and fosfomycin. Meropenem was given at an unusual high-dose (15 g/day) with the aim of achieving high CSF concentrations. CSF concentrations peaked at $64 \mathrm{mg} / \mathrm{L}$. Yet, the patient succumbed to an intracranial bleed into a preexisting cerebral contusion.
\end{abstract}

Conclusions: High-dose meropenem can achieve CSF levels largely superior to those achieved with commonly recommended dosing regimens. Though our patient succumbed to an intracranial bleed which could be regarded as a severe adverse event, we suggest that meropenem dosing can be increased when pathogens with increased MICs are found in the CSF. More in vivo data are however needed to determine the safety of high-dose meropenem.

Keywords: Meropenem, Cerebrospinal fluid, Acinetobacter baumannii, Carbapenem resistance, Meningitis, Case report

\section{Background}

Meropenem is a frequently used antimicrobial for postneurosurgical meningitis/ventriculitis [1]. It has been shown to be clinically effective [1], but its penetration into the cerebrospinal fluid (CSF) is not well characterized. The median penetration rate ranges from 9 to $39 \%$ with high inter-individual variation $[2,3]$. The efficacy of $\beta$-lactams such as meropenem depends on the percentage of the time that the unbound fraction remains above the minimum inhibitory concentration (MIC) of the microorganism. According to animal models the target for Gram-negative organisms in blood is $40-50 \%>\mathrm{fT}>\mathrm{MIC}$ [4] and an important determinant for patient outcome

\footnotetext{
*Correspondence: kerz@uni-mainz.de

${ }^{1}$ Department of Neurosurgery, University Medical Center, Langenbeckstr.

1, 55131 Mainz, Germany

Full list of author information is available at the end of the article
}

[5]. For CSF, the precise pharmacodynamic target is still subject of debate. For beta-lactam antibiotics, time above the minimal bactericidal concentration $(t>M B C)$ possibly determines the rate of bactericidal activity in CSF, and a $t>M B C$ for more than $50 \%$ of the dosing interval has been recommended [6]. Yet, no major distinction between MIC and MBC was found in several other studies [6-8], so it is open to debate if MIC or MBC need to be targeted. Meningeal inflammation facilitates the penetration of $\beta$-lactams into the CNS but most nosocomial CSF infections will only result in minimal-to-mild disturbances in the blood-CSF barrier [9].

The usual regimen of $2 \mathrm{~g}$ meropenem every $8 \mathrm{~h}$ results in CSF concentrations of $1-2 \mathrm{mg} / \mathrm{L}$ which is lower than the clinical breakpoint for susceptibility for most Gram-negative organisms [10]. Therefore, this regimen might be inadequate for the treatment of CNS infections leading to prolonged courses of treatment as well 
as patient morbidity and/or mortality. Continuous infusion of $\beta$-lactams has also been applied to ensure adequate plasma concentrations [11]. However, data on the efficacy of this regimen in meningitis/ventriculitis are scarce. Measurement of meropenem CSF concentrations has been recommended to ensure clinical efficacy in critically ill patients [2], although CSF concentrations might not exactly mirror brain tissue concentrations. We report on a high-dose meropenem regimen in a patient with a carbapenem-resistant Acinetobacter baumannii brain abscess where relevant CSF concentrations could be attained with very high-dose meropenem. To our knowledge, this is the first report on meropenem CSF concentration with such a high-dose regimen.

\section{Case presentation}

Our patient developed an intracranial abscess after placement of an external ventricular drain because of a severe brain trauma. CSF results are given in Table 1.

A carbapenemase-producing A. baumannii (OXA-23, NDM-1) was isolated from blood cultures and CSF. The MIC for meropenem was determined using a gradient test (MIC-test strip ${ }^{\circledR}$, Liofilochem, Roseto degli Abruzzi, Italy) and for colistin via commercial broth microdilution (Micronaut- $^{\circledR}$, Merlin Diagnostika, Bornheim-Hersel, Germany). European Committee on Antimicrobial Susceptibility Testing (EUCAST) breakpoints were applied. The MIC for meropenem was $>32 \mathrm{mg} / \mathrm{L}$ (R) and for colistin $\leq 1 \mathrm{mg} / \mathrm{L}(\mathrm{S})$. Colistin, fosfomycin and meropenem were given because clinical data point to improved outcomes even in carbapenem-resistant A. baumannii infections using combination therapy [12]. Meropenem was commenced with 2 g every $6 \mathrm{~h}$, and then increased initially to $10 \mathrm{~g} /$ day and then to $15 \mathrm{~g} /$ day in doses of $2 \mathrm{~g}$ given over $3 \mathrm{~h}$ with a single dose of $1 \mathrm{~g} / 3 \mathrm{~h}$ once daily, therefore allowing continuous meropenem infusion avoiding high peaks and low troughs. Meropenem concentrations in plasma and CSF were determined once daily during a $2 \mathrm{~g}$ dosing interval by HPLC-UV detection (Fig. 1). The liquid chromatographic system (Agilent 1200) consisted of an HPLC quaternary pump, a thermostated oven, a thermostated autosampler, and an UV-diode array detector. Separation was achieved at $45^{\circ} \mathrm{C}$ utilizing a Waters X-Bridge analytical column (C18;
$4.6 \times 100 \mathrm{~mm}, 3.5 \mu \mathrm{m})$. The mobile phase consisted of $20 \mathrm{mM}$ potassium dihydrogen phosphate $\mathrm{pH} 2.6$ (mobile phase A) and $20 \mathrm{mM}$ potassium dihydrogen phosphate pH 2.6 in 50\% acetonitrile (mobile phase B). Flow rate was $1.5 \mathrm{~mL} / \mathrm{min}$ and injection volume was $10 \mu \mathrm{L}$. The autosampler temperature was kept at $+4{ }^{\circ} \mathrm{C}$. UV-absorbance was monitored at $300 \mathrm{~nm}$. The gradient started at $12 \% \mathrm{~B}$ and increased to $17 \% \mathrm{~B}$ over $5 \mathrm{~min}$ and then to $50 \%$ B over $3 \mathrm{~min}$. After a washing step at $95 \%$ B for 0.5 min the column was re-equilibrated at $12 \%$ B for $3 \mathrm{~min}$. Data analysis was performed using Agilent ChemStation software. Proteins were precipitated by adding $400 \mu \mathrm{L}$ Internal Standard solution $(40 \mathrm{mg} / \mathrm{L}$ cefotaxime in acetonitrile) to $200 \mu \mathrm{L}$ serum. After vortexing precipitated proteins were separated by centrifugation. The supernatant was mixed with $3 \mathrm{~mL}$ of dichloromethane, vigorously vortexed and centrifuged. An aliquot of the upper aqueous phase was transferred to an autosampler vial for chromatographic analysis.

Since creatinine clearance has been found to be an important covariate of meropenem pharmacokinetics [13], we monitored renal function closely. The calculated glomerular filtration rate (CKD-EPI) was $\geq 50 \mathrm{~mL} /$ $\min / 1.73 \mathrm{~m}^{2}$ initially but decreased to $23-40 \mathrm{~mL} /$ $\mathrm{min} / 1.73 \mathrm{~m}^{2}$ after day 26 , most probably due to the concomitant infusion of colistin. CSF meropenem concentrations varied between 31 and $38 \mathrm{mg} / \mathrm{L}$ when $10 \mathrm{~g} /$ day were given over a time period of 12 days. The increased dosage of $15 \mathrm{~g} /$ day for 3 days resulted in a peak CSF concentration of $64 \mathrm{mg} / \mathrm{L}$ (Fig. 1). The CSF concentration of meropenem was $34-49 \%$ of the serum level. Frequent vomiting and a gastroparesis were noted as side effects whereas there was no effect on hematological or liver parameters. No assessment of central nervous side effects was possible due to the patient being in coma. Unfortunately, a massive intracranial hemorrhage into the area of contusion occurred and the patient died on day 33 .

\section{Discussion and conclusions}

Commonly recommended meropenem doses for meningitis/ventriculitis are $2 \mathrm{~g}$ every $8 \mathrm{~h}$ [14]. Yet, meropenem penetration into the brain is subject to large inter-individual variation and median penetration ratios of as low as $9 \%$ have been found [2]. Further, it is unclear which

Table 1 CSF-results during days 1-33

\begin{tabular}{|c|c|c|c|c|c|c|c|c|c|c|c|c|c|c|}
\hline Days & 1 & 5 & 8 & 12 & 15 & 19 & 19 & 23 & 26 & 29 & 33 & 33 & Unit & Normal \\
\hline Leukocyte count (CSF) & 108 & 192 & 150 & 88 & 790 & 3190 & 105 & 274 & 225 & 72 & 1470 & 540 & $/ \mu \mathrm{L}$ & $<5$ \\
\hline Erythrocyte count (CSF) & 11 & 300 & 3165 & 1452 & 9590 & 7890 & 5925 & 387 & 3100 & 997 & 34,500 & 13,630 & $/ \mu \mathrm{L}$ & 0 \\
\hline Lactate (CSF) & 6.5 & 9.7 & 8.8 & 6 & 7.4 & 9.5 & 5.8 & 5.4 & 5.7 & 5.4 & 7.7 & 7.3 & $\mathrm{mmol} / \mathrm{dL}$ & $1.7-2.6$ \\
\hline Total-protein (CSF) & 631.8 & 146.7 & 145.5 & 101.6 & 231.1 & 168.6 & 111.6 & 113.2 & 197.8 & 91.1 & 2956 & 1824.6 & $\mathrm{mg} / \mathrm{dL}$ & $15-40$ \\
\hline
\end{tabular}




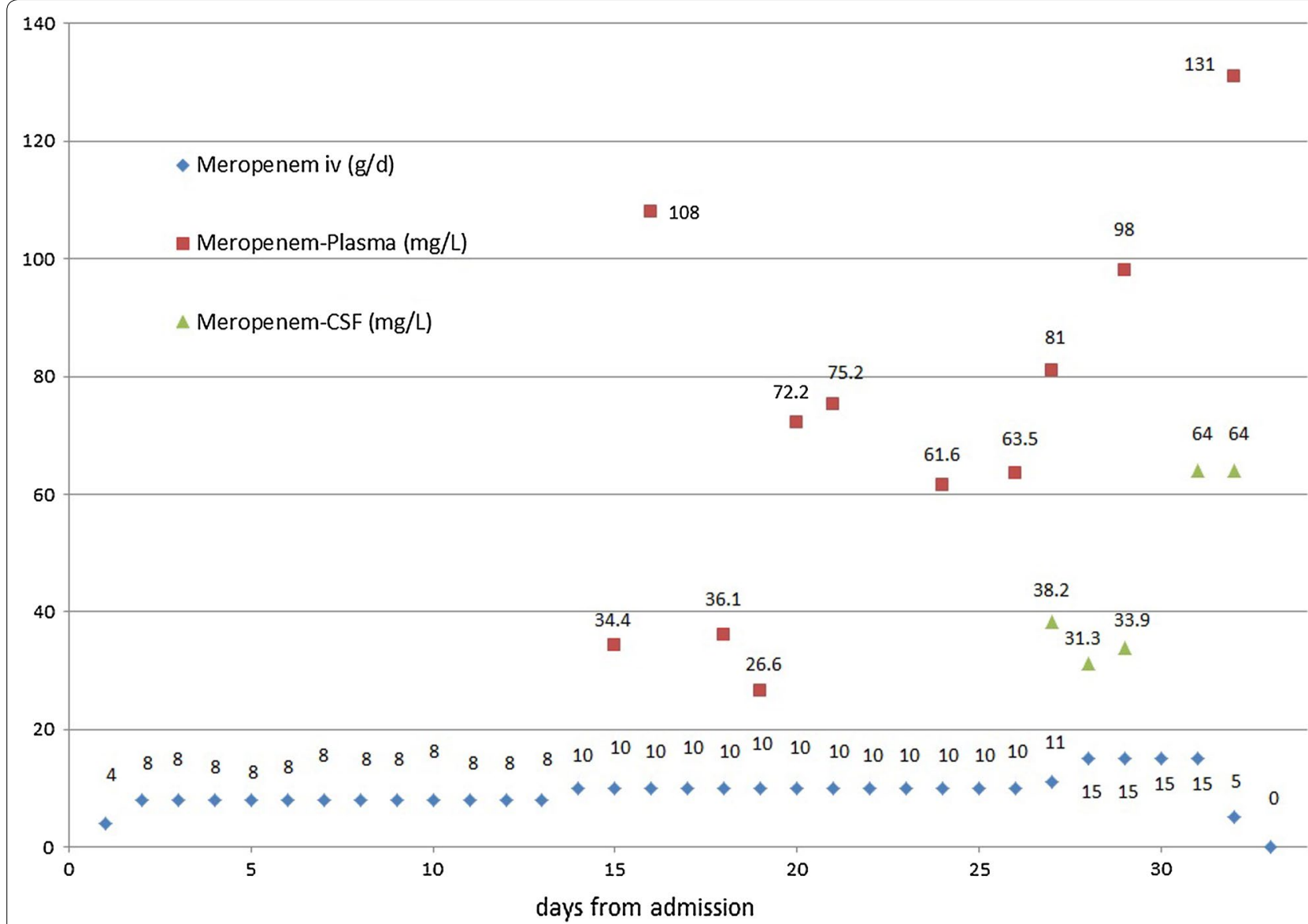

Fig. 1 Meropenem doses in g (blue diamonds) during i.v. treatment from day 0 to day 33. Meropenem plasma (red square) and CSF (green triangle) levels in $\mathrm{mg} / \mathrm{L}$, measured by HPLC-UV detection. X-axis in days, $y$-axis g/day resp. mg/L

percentage of meropenem in the CSF is in the unbound active state. Therefore, the CSF concentrations of meropenem $(6 \mathrm{~g} / 24 \mathrm{~h})$ might not be sufficient to kill bacteria with increased MIC ( $>2 \mathrm{mg} / \mathrm{L})$ [15]. An augmented renal clearance in up to two-thirds of intensive care patients possibly also contributes to under-dosing of antibiotics [16].

A prolonged 4-h meropenem infusion of $2 \mathrm{~g}$ every $8 \mathrm{~h}$ leads to a probability of a target attainment rate of $>90 \%$ for most Gram-negative organisms in the blood compartment, when the MIC of a Gram-negative organism is $\leq 8 \mathrm{mg} / \mathrm{L}$. Monte Carlo simulations suggested that, to reach this with the same dosing regimen in CSF, the MIC has to be as low as $\leq 0.5 \mathrm{mg} / \mathrm{L}$ [17]. In a pharmacokinetic model, $5 \mathrm{~g}$ meropenem every $8 \mathrm{~h}$ were needed to achieve CSF trough concentrations of $>2 \mathrm{mg} / \mathrm{L}$ in $95.1 \%$ of simulated patients [2]. Therefore, even the meropenem dose of $2 \mathrm{~g}$ every $8 \mathrm{~h}$ probably fails to achieve a reasonable target attainment rate in CSF, especially in infections with Gram-negative organisms with MICs in the intermediate or resistant range. In our patient, the use of high dose-meropenem resulted in CSF concentrations largely superior to those reported in the literature when standard dosing regimens are given. According to our results, CSF pathogens with increased meropenem MICs might be treated successfully with high-doses of meropenem, and our case suggests that an increased meropenem dosing should strongly be considered in such cases. Considering the highly variable kinetics, therapeutic drug monitoring in both serum and CSF seems indispensable to assure achievement of therapeutic drug concentrations. It is, however, unclear if the fatal bleeding was related to the high dose of meropenem. Further data are therefore necessary to determine the safety of such treatment and if dosing recommendations should be changed.

\section{Abbreviations}

CKD-EPI: Chronic Kidney Disease Epidemiology Collaboration; CNS: central nervous system; CSF: cerebrospinal fluid; EUCAST: European Committee on Antimicrobial Susceptibility Testing; fT: fraction of time; HPLC-UV: high performance liquid chromatography-ultraviolet; MIC: minimal inhibitory concentration; NDM 1: New Delhi metallo-beta-lactamase 1; OXA-23: oxacillinase-23. 


\section{Authors' contributions}

TK, FL, and AN designed and implemented the research. Together with JR and $F R$, results were analyzed and the manuscript was written. All authors read and approved the final manuscript.

\section{Author details}

1 Department of Neurosurgery, University Medical Center, Langenbeckstr. 1, 55131 Mainz, Germany. ${ }^{2}$ Department of Medical Microbiology and Hygiene, University Medical Center, Mainz, Germany. ${ }^{3}$ University of Queensland Centre for Clinical Research, Faculty of Medicine, The University of Queensland, Brisbane, QLD, Australia. ${ }^{4}$ Department of Intensive Care Medicine, Roya Brisbane and Women's Hospital, Brisbane, Australia. ${ }^{5}$ Pharmacy Department, Royal Brisbane and Women's Hospital, Brisbane, Australia. ${ }^{6}$ Centre for Translational Anti-infective Pharmacodynamics, School of Pharmacy, The University of Queensland, Brisbane, QLD, Australia.

\section{Acknowledgements}

Not applicable.

\section{Competing interests}

The authors declare that they have no competing interests.

\section{Availability of data and materials}

All data generated or analyzed during this study are included in this published article.

\section{Consent for publication}

Consent for publication of anonymized data was obtained from the patient.

\section{Ethics approval and consent to participate}

A waiver of informed consent was granted by our institutional review board (Ethikkommission Rheinland-Pfalz).

\section{Funding}

This study did not receive any specific grant.

\section{Publisher's Note}

Springer Nature remains neutral with regard to jurisdictional claims in published maps and institutional affiliations.

Received: 24 October 2018 Accepted: 21 December 2018

Published online: 29 December 2018

\section{References}

1. Schmutzhard E, et al. A randomised comparison of meropenem with cefotaxime or ceftriaxone for the treatment of bacterial meningitis in adults. Meropenem Meningitis Study Group. J Antimicrob Chemother. 1995;36(Suppl A):85-97.
2. Blassmann $U$, et al. Cerebrospinal fluid penetration of meropenem in neurocritical care patients with proven or suspected ventriculitis: a prospective observational study. Crit Care. 2016;20(1):343.

3. Dagan $\mathrm{R}$, et al. Penetration of meropenem into the cerebrospinal fluid of patients with inflamed meninges. J Antimicrob Chemother. 1994;34(1):175-9.

4. EUCAST. Meropenem: rationale for the EUCAST clinical breakpoints, version 1.5. EUCAST; 2009.

5. Levison ME, Levison JH. Pharmacokinetics and pharmacodynamics of antibacterial agents. Infect Dis Clin North Am. 2009;23(4):791-815, vii.

6. Andes DR, Craig WA. Pharmacokinetics and pharmacodynamics of antibiotics in meningitis. Infect Dis Clin North Am. 1999;13(3):595-618.

7. Decazes JM, Ernst JD, Sande MA. Correlation of in vitro time-kill curves and kinetics of bacterial killing in cerebrospinal fluid during ceftriaxone therapy of experimental Escherichia coli meningitis. Antimicrob Agents Chemother. 1983;24(4):463-7.

8. Lutsar l, et al. Pharmacodynamics and bactericidal activity of ceftriaxone therapy in experimental cephalosporin-resistant pneumococcal meningitis. Antimicrob Agents Chemother. 1997;41(11):2414-7.

9. Lutsar I, McCracken GH Jr, Friedland IR. Antibiotic pharmacodynamics in cerebrospinal fluid. Clin Infect Dis. 1998;27(5):1117-27 (quiz 1128-9).

10. Zhang $Y$, et al. Evaluation of meropenem penetration into cerebrospinal fluid in patients with meningitis after neurosurgery. World Neurosurg. 2017:98:525-31.

11. Mader MM, et al. Intrathecal penetration of meropenem and vancomycin administered by continuous infusion in patients suffering from ventriculitis - a retrospective analysis. Acta Neurochir. 2018;160(11):2099-105.

12. Shields RK, et al. Epidemiology, clinical characteristics and outcomes of extensively drug-resistant Acinetobacter baumannii infections among solid organ transplant recipients. PLoS ONE. 2012;7(12):e52349.

13. Cojutti $P$, et al. Population pharmacokinetics of high-dose continuousinfusion meropenem and considerations for use in the treatment of infections due to KPC-producing Klebsiella pneumoniae. Antimicrob Agents Chemother. 2017;61(10):e00794-17. https://doi.org/10.1128/ AAC.00794-17.

14. Tunkel AR. Initial therapy and prognosis of bacterial meningitis in adults. 2017 2017-05-01. https://www.uptodate.com/contents/initial-thera py-and-prognosis-of-bacterial-meningitis-in-adults\#H10. Accessed 26 Jan 2017

15. Nau R, et al. Disposition and elimination of meropenem in cerebrospinal fluid of hydrocephalic patients with external ventriculostomy. Antimicrob Agents Chemother. 1998;42(8):2012-6.

16. Hobbs AL, et al. Implications of augmented renal clearance on drug dosing in critically ill patients: a focus on antibiotics. Pharmacotherapy. 2015;35(11):1063-75

17. Lu C, et al. Population pharmacokinetics and dosing regimen optimization of meropenem in cerebrospinal fluid and plasma in patients with meningitis after neurosurgery. Antimicrob Agents Chemother. 2016;60(11):6619-25.
Ready to submit your research? Choose BMC and benefit from:

- fast, convenient online submission

- thorough peer review by experienced researchers in your field

- rapid publication on acceptance

- support for research data, including large and complex data types

- gold Open Access which fosters wider collaboration and increased citations

- maximum visibility for your research: over $100 \mathrm{M}$ website views per year

At BMC, research is always in progress.

Learn more biomedcentral.com/submissions 